\title{
Plasmablastic Lymphoma
}

\author{
Subecha Bhusal,' Bibek Acharya,' Sandhya Chapagain' \\ 'Department of Clinical Oncology, Bir Hospital, National Academy of Medical Sciences, Kathmandu, Nepal.
}

\begin{abstract}
Plasmablastic lymphoma is a rare and aggressive lymphoma reported to be commonly associated with immunodeficiency state. It possesses a challenge to the clinician owing it aggressiveness and poor prognosis. No standard of care treatment is available for the disease. Here we report a case of an immunocompetant 67 years female who is unique in her presentation as she did not have any of the conventional clinical features and had a history of urothelial carcinoma three months back.
\end{abstract}

Keywords: plasmablastic lymphoma; urothelial carcinoma; SVCO.

\section{INTRODUCTION}

Plasmablastic lymphoma (PBL) is a relatively new clinical entity described as a distinct subtype of diffuse large B-cell lymphoma (DLBCL), characterized by its aggressive nature and plasmacytic differentiation. ${ }^{1}$ This rare entity was initially described in 1997 by Delecluse and colleagues. ${ }^{2}$ In this study, 16 cases were described with morphological features of DLBCL but with a lack of CD20 and CD45 expression. These cases showed a plasmacytic differentiation based on the expression of VS38c and cytoplasmic immunoglobulin. Their B-cell lineage was demonstrated through the presence of $\mathrm{Ig}$ gene rearrangements. Fifteen of these patients (94\%) were infected with the human immunodeficiency virus (HIV), and they all presented with involvement of the oral cavity. Epstein-Barr virus (EBV)-encoded RNA (EBER) was expressed in nine patients (60\%). Since then many cases have been reported in the literature of HIV negative patients and extra nodal presentations in PBL. However some form of immunosupression either as post organ transplantation status or infection with EBV has been noted in most HIV negative patients. ${ }^{1,3}$

\section{CASE REPORT}

A 67 years female presented to Bir Hospital with complain of shortness of breath for a day with burning type pain in left upper limb and on and off burning micturation. She had past medical history of NSTEMI for which $\mathrm{PCl}$ was done two months back. She also had history of papillary urothelial carcinoma, low grade for which TURBT was done three months back. Her physical examination revealed a $5 \times 5 \mathrm{~cm}$ right supraclavicular and $8 \times 8 \mathrm{~cm}$ left axillary mobile hard mass with decreased air entry bilaterally, normal looking oral cavity. Electrocardiography showed normal findings. Computerized tomography scan of neck and chest showed few right level $V$ cervical lymphadenopathy (largest nodule- $3.5 \times 2.5 \mathrm{~cm}$ ); large enhancing $(10.7 \times 6.3 \times 6.1 \mathrm{~cm})$ soft tissue in upper mediastinum with encasement of mediastinal great vessels; enhancing soft tissue density mass $16 \times 6 \times 5.2$ $\mathrm{cm}$ ) in lower lobe extending up to right hilum with another small satellite nodule in lateral basal segment of right lower lobe; enhancing soft tissue in right apical pleura with erosion of adjacent right 2 nd rib-likely metastasis. Biopsy from the cervical lymph node was compatible with Non Hodgkin's Lymphoma, Diffuse large cell type. Ki-67 and EMA were immunoreactive with a score of $4+$ in large atypical cells. Also, CD138 and Bcl-6 were

Correspondence: Dr. Subecha Bhusal, Department of Clinical Oncology, Bir Hospital, National Academy of Medical Sciences, Kathmandu, Nepal. Email: bhsubecha@gmail.com, Phone: +977. 9841824973 
immunoreactive. CD3, CD20, CD10, CD30, ALK-1, CD56 were non-immunoreactive. She had persistent hyponatremia with lowest recorded being $97 \mathrm{mmol} / \mathrm{l}$. HIV antibodies were tested to be negative. Ebstein Barr Virus could not be tested due to financial constraints. She had no history of intake of any immunosuppressive medicines. Based on the clinical presentation, morphology and immunophenotype the patient was diagnosed to have plasmablastic lymphoma. The patient was started on palliative radiation to supraclavicular mass as she had developed features of superior vena caval obstruction with plans for chemotherapy when her general condition improves but unfortunately, she died during the course of radiation due to respiratory failure.

\section{DISCUSSION}

PBL is thought to account for approximately $2.6 \%$ of all AIDS-related lymphomas (ARLs) although the exact rate of incidence is not known. ${ }^{1}$ The majority of patients with PBL are men, particularly the HIV-positive cases, with a mean age at presentation of 39 years in HIV-positive patients and 58 years in HIV-negative patients. ${ }^{4}$ It is morphologically similar to diffuse large B-cell lymphoma (DLBCL). It probably arises from a post-germinal center $B$ cell, related to Epstein-Barr virus (EBV) but not to human herpes virus 8 , as opposed to primary effusion lymphoma. ${ }^{5}$ DLBCL is the most common type of B-cell lymphoma and accounts for $41 \%$ of the cases of NHL. ${ }^{6}$ There are several morphologic variants of DLBCL including centroblastic, immunoblastic, anaplastic, T-cell/histiocyte rich, and PBL. ${ }^{6}$ The spectrum of DLBCL with plasmablastic features has widened to include subtypes, such as PBL of oral mucosa type, PBL with plasmacytic differentiation, classic PEL, extracavitary/ solid PEL or HHV8-associated DLBCL, and ALK-positive DLBCL. ${ }^{6,7} \mathrm{PBL}$ is a distinct subtype of DLBCL, that is, characterized by an immunoblastic and/or plasmablastic morphology, Ig heavy chain gene rearrangement, and consistent expression of plasma cell antigens. Advances in immunophenotyping have helped greatly when differentiating PBL from other neoplasms. The hallmark immunohistochemical staining pattern of
PBL is that of terminally differentiated B lymphocytes. PBL demonstrates little to no expression of leukocyte common antigen (CD45) or the B-cell markers CD20, CD79a, and PAx5. However, the plasma cell markers VS38c, CD38, multiple myeloma oncogene-1 (MUM1), and CD138 (syndecan-1) seem to be almost universally expressed.

PBL has been characterized for its predilection of involving the oral cavity of HIV-positive individuals due to high predilection of chronic oral premalignant lesions in these group of patients. ${ }^{4}$ However, extraoral involvement is also frequently seen in HIV-positive cases; the most commonly affected sites are the gastrointestinal tract, lymph nodes, and skin. ${ }^{7}$ Other less common extraoral sites include the CNS, paranasal sinus, mediastinum, lungs, liver,breast,anal canal and testes. ${ }^{1,8}$

In both HIV-positive and -negative patients, $60 \%$ of patients present with an advanced clinical stage i.e., Ann Arbor stage 3 or $4 .{ }^{4} \mathrm{~B}$ symptoms have been reported in $33 \%$ of HIV-positive and $50 \%$ of HIVnegative patients at diagnosis. ${ }^{4}$

There is no standard chemotherapy protocol available for PBL. Anthracycline based protocols (Cyclophosphamide, Adriamycin, Vincristine, Prednisolone (CHOP) or CHOP like) have been used but due to disappointing response and survival rates, the NCCN guidelines recommend against $\mathrm{CHOP}$ in favor of more intensive regimens, such as infusional $\mathrm{EPOCH}, \mathrm{HyperCVAD}$, or CODOX-M/IVAC. A large literature review of treated cases of PBL showed an overall response rate (ORR) to chemotherapy of $77 \%$, with $46 \%$ of patients achieving a complete response (CR) and $31 \%$ a partial response (PR). ${ }^{1,9}$ Patients with PBL who were not treated with chemotherapy invariably died with a median survival of 3 months. $^{9}$

\section{Conflict of Interest: None.}

Consent: JNMA Case Report Consent Form was signed by the patient and the original is attached with the patient chart.

\section{REFERENCES}

1. Castillo JJ, Reagan JL. Plasmablastic lymphoma: a systematic review. Scientific World Journal. 2011 Mar 22;11:687-96. [PubMed | DOI]
2. Delecluse HJ, Anagnostopoulos I, Dallenbach F, et al. Plasmablastic lymphomas of the oral cavity: a new entity associated with the human immunodeficiency virus infection. Blood. 1997;89(4):1413-20. [PubMed | Fulltext] 
3. Liu F, Asano N, Tatematsu A, Oyama T, Kitamura K, Suzuki K, et al. Plasmablastic lymphoma of the elderly: a clinicopathological comparison with age-related Epstein-Barr virus-associated B cell lymphoproliferative disorder. Histopathology. 2012;61(6):1183-97. [PubMed | DOI]

4. Castillo JJ, Winer ES, Stachurski D, Perez K, Jabbour M, Milani C, et al. Clinical and pathological differences between human immunodeficiency virus-positive and human immunodeficiency virus-negative patients with plasmablastic lymphoma. Leuk Lymphoma. 2010 Nov;51(11):2047-53. [Full Text | DOI]

5. Sharma A, Tilak TV, Lodha R, Sharma MC, Dabkara D. Long-term survivor of human immunodeficiency virus-associated plasmablastic lymphoma. Indian journal of medical and paediatric oncology: official journal of Indian Society of Medical \& Paediatric Oncology. 2013;34(2):96-8. [PMC | DOI]
6. Campo E, Swerdlow SH, Harris NL, Pileri S, Stein H, Jaffe ES. The 2008 WHO classification of lymphoid neoplasms and beyond: evolving concepts and practical applications. Blood. 2011;117(19):5019-32. [PubMed | Fulltext]

7. Castillo J, Pantanowitz L, Dezube BJ. HIV-associated plasmablastic lymphoma: lessons learned from 112 published cases. Am J Hematol. 2008 Oct;83(10):804-9. [PubMed | Fulltext]

8. Nicol I, Boye T, Carsuzaa F, Feier L, Collet Villette AM,Xerri L, et al. Post-transplant plasmablastic lymphoma of the skin. Br J Dermatol. 2003;149:889-91. [PubMed | Fulltext]

9. Castillo JJ, Winer ES, Stachurski D, Perez K, Jabbour M, Milani C, et al. Prognostic Factors in Chemotherapy-Treated Patients with HIV-Associated Plasmablastic Lymphoma. The Oncologist. 2010;15(3):293-9. [PubMed | PMC | DOI] 